\title{
Intrahepatic Bile Duct Papillary Neoplasm
}

National Cancer Institute

\section{Source}

National Cancer Institute. Intrahepatic Bile Duct Papillary Neoplasm. NCI Thesaurus.

Code C7125.

A non-invasive, papillary epithelial neoplasm that arises from the epithelium of the intrahepatic bile ducts. 